\title{
DIFFERENTIAL DIAGNOSIS IN AXIAL BACK PAIN AT CHILD
}

\author{
Leo Stati \\ Department of Pediatric Surgery, “N. Testemitanu” Orthopedics and Anesthesiology \\ USMF, Chisinau, Republic of Moldova
}

\begin{abstract}
Most cases of back axial pain of the child, are lying on the border between pathology and surgical medical specialties.

Continuous pain lasting more than two weeks can be a sign of severe pathologies, imposing the urgent clinical, laboratory and imaging investigation.

It identifies several causes that can produce axial back pain in childhood: Scheuermann's disease, symptomatic scoliosis (secondary), spondylolysis, spondylolisthesis, spondylodiscitis, sacroileitis, fractures of the column, spine tumors and rheumatic spondyloarthropathies.
\end{abstract}

Keywords: back pain, child, causes

In the last decades it has been observed negative trends in the dynamic parameters of the health of children and adolescents. The most significant increase in morbidity are recorded in children of school age. Under the intensification of the educational process in an unfavorable hygienic social background and a complicated ecological situation, the child's body requires an increased physical activity, which is missing from the factors listed (1.2).

According to the National Bureau of Statistics of the Republic of Moldova in 2008, 727,500 youngsters were undergoing screening aiming axial back pain; $8.5 \%$ were found sufferers, an enough high percentage to be worrisome.

Congruent to the international classifications the algic syndrome within the spine diseases is included in the $13^{\text {th }}$ group (diseases of the locomotive system and the conjuntive tissue). In the contemporary medical literature the vertebrogenic algic syndrome, with any kind of affection of the peripheral nervous system is concedered as a pathology of the locomotive system.

Clinical experience gained in the diagnosis of these diseases shows that practicing physicians are insufficiently informed about the pathology of "back pain" due to musculoskeletal disorders, including spine, and other extra-vertebral disorders.
If back pain persists for more than 2 weeks and/ or are troublesome during physical activities it is necessary diagnostic evaluation. In addition to a the correct anamnesis the physical examination assesses the global health status of the child, associating general signs (fever, weight loss), sometimes neurological changes and/or other organs.

In the University Clinic of primary health care, pediatric orthopedics department and department of family medicine at the University "N. Testemitanu" from Chisinau, during two years (2014 and 2015) were examined orthopedic 1500 children between $7-18$. Back pain was detected in $9 \%$ of the total (unpublished data).

The guidance of paraclinical examinations includes tests for possible inflammatory syndrome, immunological assessment and radiography imaging examinations starting from column to the detailed explorations (scintigraphy, computed tomography, MRI) when progression of the disease require. The basic radiological methods in the diagnosis of back pain and scoliosis, well known and widely used in pediatric orthopedics is not recommended for examination in mass and dynamic monitoring of children and adolescents, due to high levels of carcinogenic risk to growing body. 
Although various methods of instrumental examination orthopedic patients have seen the great development, clinical examination remains essential. Orthopedic examination is performed in orthostatic position (from behind, front and profile), seated and lying down (2).

There is characteristic clinical signs associated with back pain by etiology. Low back pain may be accompanied by urinary incontinence or neurological disorders of the lower limbs (cutaneous hyposensitation, paraesthesia). This specific symptoms require urgent investigation.

Neurological disorders are detected through examination of sensitivity and motility (2).

It is known that various dysplastic, degenerative-dystrophic, traumatic and inflammatory disorders headquartered in the backbone, that are manifested by a painful syndrome in the back region $(2,3)$.

Scheuermann disease (4), framed in the avascular bone necrosis group, with unknown cause, it is the most common disease that is accompanied by pain spine in adolescents. Symptoms associated with pain beside injured vertebrae and kyphotic progressive curvature. The usual location is in the middle thoracic vertebrae $\left(\mathrm{T}_{7}-\mathrm{T}_{9}\right.$, but sometimesbelow $\mathrm{T}_{9}-\mathrm{T}_{12}$ level). Lumbar forms are exceptional.

The pain is so spontaneous and to the flexion and extension of the spine and spinous apophyses percussion. Its intensity is variable, sometimes without. The lack of parallelism between pain and kyphosis degree makes kyphosis after recovery to persist with or without associated pain.

The lombar location usualy evolves without pain in adolescence, but during young adulthood the intervertebrale discs are getting fragile and leades to early occurrence of lumbar spondilatroze.

The clinical diagnosis for suspecting Scheuermann disease is confirmed radiologically by the appearance of irregular surfaces vertebral body, clamping disc, anterior cuneiforming vertebral body and appearance of Schmorl nodules (the radiological characteristic symptom).

Essential scoliosis $(4,5)$ is a condition which is rarely accompanies by pain. When scoliosis is installed on a painful posterior axial background recently appeared, it is a secondary type scoliosis, symptomatic.

The main cause of pain is common neighborhood infection (perinephric abscess) that causes ipsilateral muscle stiffness with the appearance of spinal curvature in the frontal plane, having curvature with convexity in the opposite direction. Likewise act and an expansive intracanal vertebral tu- mor process, which in addition can accompany spinal compression with neurological disorders.

Spondylolysis $(4,6)$ is considered at the moment to be a stress fracture and consists in the apearace of a substace at the level of the vertebral isthmus unilateral or bilateral, L4 or L5 level.

Lower-back pain is the dominant symptom, it can appeare both spontaneous and especially during the movement of the trunk extension and axial rotation. Unilateral spondylolysis may be asymptomatic, and discovered by chance during an X-ray done for another purpose.

Lumbar spine radiography in oblique incidence, highlights the line of osteolysis in the vertebral isthmus. Surest diagnostic image is obtained by CT scan.

Recovery is achieved within 4-6 weeks with rest and immobilization of the lumbar spine using an appropriate orthotics. Bilateral spondylolysis may have an underlying vertebral displacement of the block, Insitu the spondylolisthesis. The risk of medullary compression in this case makes the treatment to be more aggressive, imposing the blockade spine through arthrodesis.

Spondylodiscitis (7) is infection of the intervertebral disc and vertebral body adjacent to banal pyogenic germs (the old name of "vertebral osteomyelitis") or Koch bacillus (Crohn's Pott). In 70\% of cases banal germ infection affects the lumbar region; TB infection prevalence is more at the thoracic spine.

Symptoms consist of rahialgia sometimes lameness, moderate fever $\left(38^{0}-39^{\circ}\right)$. Spinous percussion in the affected area is painful. Spontaneous pain is often nocturnal and is not relieved by rest.

Radiological image appears later as osteomyelitis and other locations. Spinal caries appear first, then pinching the intervertebral disc. This proves that the infection is initially bone, then send the disc. CT scan reveals better and early lesions.

Spinal tuberculosis infection is increasingly rare today.

Sacroileitis (8) is an infection by nonspecific germs of the sacroiliac joint and bone mountainside of the joint.

Low back pain in general symptoms are very similar to the L4-L5 spondilodiscita.

Radiography is apeares later with some irregularities and bone cavities especially the iliac side of the joint, accompanied by pinching joint space.

For early diagnosis is very useful scintigraphy with $\mathrm{Tc}_{99}$.

Fractures of the spine are common in road accidents and falls from height. Currently extreme sports can have the same consequences. 
Fracture may involve the vertebral body through compaction, more rarely posterior neural arch bone. Damage is translated as disk failure or crushing.

The existence of injury, the back pain, sometimes neurological and radiological examination positive signs are sufficient for diagnosis.

Disc herniation accompanied by sciatic syndrome is rare in children.

Posture pain. In a regular sports activities dorsal muscles can work with different intensities, leading to greater fatigue on the part of some. It causes pain and secondary change posture, which in turn accentuates the pain.

Spinal holes stenosis through which spinal nerves exit may have different causes; nerve root compression resulting neurological symptomatic. Idiopathic back pain is a diagnosis to be made carefully, after excluding any possible causes behind complex investigations.

Fibromyalgia, a chronic non-inflammatory disease is common in adolescents. Translates by diffuse muscle pain, including dorsal axial trunk, fatigue, cognitive dysfunction, sleep disorders, anxiety, depression. At the central level increased sensitivity to pain, which translated by:

- hyperalgesia, pain that is disproportionate to the scale factor aggressor.

- allodynia manifests itself through painful sensitivity to stimuli that ordinarily do not cause pain (touch).

Rachis tumors in $80 \%$ of cases are benign: the most frequently met is eosinophilic granuloma, then osteoblastoma, osteoid osteoma and aneurysmal bone cyst. Symptoms consist of rachialgies accompanied by segmental stiffness of the column $(5,6)$.

Eosinophilic granuloma is localized in the vertebral body and its frustrating symptom makes it often to be found in the skeleton stage under the form of flattening body (the former "vertebra plana" of Calvé).

Osteoblastoma and osteoid osteoma localises at the level of the poterior arch and when the pain did not support visible ray, scintigraphy reveals intense hyperfixation. Later radiological image of osteolysis appears sometimes with a blower character.

Aneurysmal bone cyst has the same look osteolytic radiologic blast, but the location of choice is the vertebral blade and transverse apophysis.

Spinal soft tissue tumors varies with location:

- Intradural-extramedullary tumors: meningioma (rarely is malignant) tumors of the nerve sheath and spinal roots, always benign (schwannoma, neurofibroma).
- Intraspinal tumors: glioma with the usual cervical location, very difficult to remove surgically.

Ewing's sarcoma, the most common malignant spinal tumor pain often associated neurological symptoms. Located in the posterior neural arch of the vertebra, and has the appearance of a radiological osteolytic formations, more or less oval. Preoperative MRI is necessary to assess the extension into neighboring soft parts.

Osteosarcoma is rarely localized in vertebrae and occurs in teenagers.

Metastatic tumors are very rare in children.

Juvenile spondyloarthropathies (9-12) are a group of conditions belonging to the child's chronic rheumatism (onset before age 16 years) with the common traits: spinal pain, chest, buttocks and/or morning stiffness or lumbar dorsal arthritis (large joints), enthesitis, talalgie, hammer toes, thickened. Other events associated variable: acute iritis, urethritis or cervicitis non-gonococcal, diarrhea, presence or history of psoriasis, the balance, chronic entero-colopatie. The differences in clinical course features, associations lesion, presence of risk factors outlined the following clinical forms: spondylarthropathy undifferentiated, ankylosing spondylitis (pelvispondylitis), reactive arthritis, psoriatic arthritis and rheumatism chronic enterocolopathy.

In undifferentiated spondylarthropathy the most common inaugural symptoms are arthralgia, limb arthritis (monoarthritis, oligoarthritis, rarely arthritis) and enteziopatiile. Axial lesions can occur after years of development. Axial pain may be spontaneous or accused should be sought. In order of frequency was reported: back pain, buttock (sacroiliac arthritis), dorsalgias, back cervicalgii.

In rheumatic pelvispondilytis (ankylosing spondylitis juvenile) axial damage is rare at onset (10$20 \%$ ), the clinical picture is dominated by peripheral arthritis and enteziopatie. The pain worsens progressively axial but disappear after installing stiffness.

Psoriatic rheumatism attested by the presence of psoriasis and/or family history of psoriasis associated with lumbosacral pain and/or hip by sacroiliac pain in other large joints.

In the enterocolopathy rheumatism pain in the spine and sacroiliac joints may occur at different times in relation to colitis (sometimes after it's improvement).

\section{CONCLUSIONS}

Back pain with persistent character (several weeks) in children with a wide etiological range 
and enrolling as a single symptom of a clinical entity, differential diagnosis is involved laboriously.

Early detection and diagnosis correct classification of back pain in children remains a serious problem in orthopedics today. Lack of regular med-

\section{REFERENCES}

1. Marin I. Defectele ținutei, scoliozele, prevenirea şi tratamentul la copii, Chişinău: Cartea Moldovenească, 1969, p. 12

2. Caproş N. Elemente de patologie a coloanei vertebrale, Chişinău: Edit-Prest, 2009, p. 152

3. Antonescu D. Diformitățile coloanei vertebrale. Scolioze-cifoze: Patologia aparatului locomotor., 2 ed., vol. II, Bucureşti: Editura medicală, 2008, pp. 164-265

4. Lovell W.W., Winter R.B. Pediatric Orthopaedics. Ed. J.B. Lippincott Company, 1986

5. Tachdjian M.O. Clinical Pediatric Orthopedics. The Art of Diagnosis and Principles of Management. Ed. Appleton \& Lange, 1997

6. Goția Stela, Durerea acută şi cronică la copil. Ed. Vasiliana'98, 2009

7. Dormans J.P. Pediatric orthopaedics: Core Knowledge in Orthopaedics. Ed. Mosby, 2005 ical examinations in schools, children with back pain and deformities of the spine are often omitted, remaining without attention from parents, teachers and doctors.
8. Benson M.K.D., Fixsen J.A., Macnicol M.F. Children's Orthopaedics and Fractures. Ed. Churchil Livingstone, 1994

9. Deslandre C.J. Les arthrites juvenileidiopathique. Spondilarthropathie juvenile. La Presse Medicale. 2000, 29, 9, 510-515

10. Goția Stela, Ailioaie C., Ailioaie Laura, Boli reumatismale şi kinetoterapia la copil. Ed. Tehnopres, 2004

11. Dougades M., Van der Linden S., Juhlin R. et al. The European Spondilarthropathies Study Groups. Preliminary criteria for the classification of the spondilarthropaty. Arthritis Reum. 1991, 34, 1218-1227

12. Prieur A.M. Rheumatologie pediatrique. Ed. Medecine-Science Flammarion, 1999 